\title{
BIPLANAR IMAGING WITH TRIDIMENSIONAL CAPABILITIES: APPLICABILITY OF THIS NEW EXAMINATION TO SPINAL DEFORMITIES
}

\author{
IMAGEM BIPLANAR COM CAPACIDADE TRIDIMENSIONAL: APLICABILIDADE DO NOVO \\ EXAME NAS DEFORMIDADES NA COLUNA VERTEBRAL
}

\section{IMAGEN BIPLANAR CON CAPACIDAD TRIDIMENSIONAL: APLICABILIDAD DEL NUEVO EXAMEN EN LAS DEFORMIDADES EN LA COLUMNA VERTEBRAL}

\author{
Raphael de Rezende Pratali, ${ }^{1}$ Murilo Tavares Daher, ${ }^{2}$ Robert Meves ${ }^{3}$ \\ 1. Hospital do Servidor Público Estadual, São Paulo, SP, Brazil. \\ 2. Centro de Reabilitação e Readaptação Dr. Henrique Santillo (CRER), Goiânia, GO, Brazil. \\ 3. Santa Casa de São Paulo, Faculdade de Ciências Médicas (FCMSCSP), São Paulo, SP, Brazil.
}

\begin{abstract}
This study presents details about the applicability of the new image acquisition system, called the biplanar imaging system, with threedimensional capabilities $\left(E O S^{\circledR}\right)$ to the treatment of spinal deformities. This system allows radiographic acquisition of the entire body, with a great reduction in the dose of radiation absorbed by the patient and three-dimensional (3D) stereoradiographic image reconstruction of bone structures, including the spine. In the case of adolescent idiopathic scoliosis, the analysis of the spinal deformity with 3D reconstruction allows better understanding of the deformity and surgical planning. In the case of adult spinal deformity, full-body analysis allows an evaluation of the spinopelvic deformity, including loss of sagittal alignment, in addition to an evaluation of compensatory mechanisms recruited by the individual in an attempt to maintain the sagittal balance. Level of evidence III; Descriptive Review.
\end{abstract}

Keywords: Radiography; Technology, Radiologic; Spine; Scoliosis; Bone Malalignment.

\section{RESUMO}

O presente estudo apresenta detalhes sobre a aplicabilidade do novo sistema de aquisição de imagem, denominado sistema de imagem biplanar, com capacidade tridimensional $\left(E O S^{\circledR}\right)$ no tratamento de deformidades da coluna vertebral. Tal sistema permite a aquisição radiográfica do corpo inteiro, com grande redução da dose de radiação absorvida pelo paciente e reconstrução estereoradiográfica em imagem tridimensional (3D) das estruturas ósseas, incluindo a coluna vertebral. No caso de escoliose idiopática do adolescente, a análise da deformidade da coluna vertebral com reconstrução 3D permite a melhor compreensão da deformidade e planejamento cirúrgico. No caso da deformidade da coluna vertebral do adulto, a análise do corpo inteiro permite a avaliação da deformidade espinopélvica, incluindo a perda do alinhamento sagital, além da avaliação adicional dos mecanismos compensatórios recrutados pelo indivíduo na tentativa de manter o equilíbrio sagital. Nível de evidência III; Revisão Descritiva.

Descritores: Radiografia; Tecnologia Radiológica; Coluna Vertebral; Escoliose; Mau Alinhamento Ósseo.

\section{RESUMEN}

El presente estudio presenta detalles sobre la aplicabilidad del nuevo sistema de adquisición de imagen denominado sistema de imagen biplanar, con capacidad tridimensional (EOS $\left.{ }^{\circledR}\right)$ en el tratamiento de deformidades de la columna vertebral. Tal sistema permite la adquisición radiográfica del cuerpo entero, con gran reducción de la dosis de radiación absorbida por el paciente y reconstrucción estereorradiográfica en imagen tridimensional (3D) de las estructuras óseas, incluyendo la columna vertebral. En el caso de escoliosis idiopática del adolescente, el análisis de la deformidad de la columna vertebral con reconstrucción 3D permite la mejor comprensión de la deformidad y planificación quirúrgica. En el caso de la deformidad de la columna vertebral del adulto, el análisis del cuerpo entero permite la evaluación de la deformidad espinopélvica, incluyendo la pérdida de la alineación sagital, además de la evaluación adicional de los mecanismos compensatorios reclutados por el individuo en el intento de mantener el equilibrio sagital. Nivel de evidencia III; Revisión Descriptiva.

Descriptores: Radiografía; Tecnología radiológica; Columna vertebral; Escoliosis; Desviación ósea.

\section{INTRODUCTION}

The technology devised by Professor Georges Charpak, ${ }^{1}$ winner of the 1992 Nobel Prize in Physics, enabled the development of a new image acquisition system, known as the three-dimensional capacity biplanar imaging system $\left(\mathrm{EOS}^{\circledR}\right) .^{2}$ Based on an ultrasensitive $\mathrm{X}$-ray detector, the system is capable of limiting the dose of radiation absorbed by the patient, in addition to allowing simultaneous image capture in the anteroposterior (AP) and lateral (L)

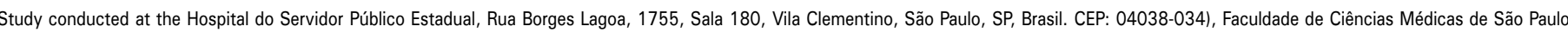

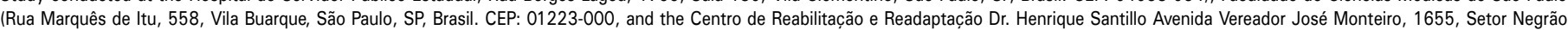
de Lima, Goiânia, GO, Brasil. CEP: 74653-230.

Correspondence: Raphael de Rezende Pratali. Rua Borges Lagoa, 1755, Sala 180, Vila Clementino, São Paulo, SP, Brasil. CEP: 04038-034. pratalir@gmail.com 
two-dimensional (2D) planes of the entire body. ${ }^{2-5}$ Simultaneous acquisition of the image in two planes, when performed in a calibrated environment, also allows stereoradiographic reconstruction of the bone structures and of the spine in a three-dimensional (3D) image. $^{2-5}$ (Figure 1)

With a biplanar imaging system, whole body image acquisition is performed rapidly, in around 30 seconds $^{2}$ and with a dose of radiation about 10 times lower than for full spinal radiography. Another advantage is life-size imaging without magnification due to simultaneous capture by two X-ray sources. ${ }^{5}$ Finally, one of the main features of this imaging system is the ability to obtain images of bone structures with 3D reconstruction through acquisition in two planes. This capability depends on the software that uses algorithms based on statistical models and bone element shape recognition and a well-trained operator to identify key points in the shape of the bone elements in question. . $^{3,4}$

The use of biplanar imaging has evolved considerably in recent years with increasing practical applicability, especially in the evaluation of spinal disorders. ${ }^{5}$ The objective of this article is an updated presentation and discussion of the benefits of skeletal image acquisition using a biplanar imaging system, considering spinal deformities in both pediatric and adult patients.

Adolescent Idiopathic Scoliosis (AIS) is the most common spinal deformity in clinical practice and affects from 1.5 to $3 \%$ of adolescents. ${ }^{8}$ Although the definition only takes the coronal plane (angulation greater than $10^{\circ}$ ) into account, ${ }^{8}$ it is known as a threedimensional deformity, in which there is torsion of the spine and the entire trunk. ${ }^{9}$

Recognition of the three-dimensional characteristics of this deformity has enabled the evolution of fixation systems as observed over the last few decades, from the Harrington distraction rods of the 60s (uniplanar correction) to the segmental fixation systems with Luque wires of the 70s (biplanar correction) to the Cotrell-Dubousset hooks and derotation maneuvers of the 80 s (triplanar correction). ${ }^{10}$ More recently, with the advent of pedicle screws, this correction has been optimized, allowing direct derotation of the vertebrae at the apex of the deformity. ${ }^{11}$

However, despite the great progress observed in the treatment of this deformity, the propaedeutics remain practically unchanged, with simple radiographs basically being the only examination used for diagnosis, classification, and therapeutic planning. ${ }^{12}$ The characterization of scoliosis, a three-dimensional deformity, by means of radiography, a two-dimensional method, has some limitations, the main ones being quantification of apical vertebral rotations (AVR) and measurement of the curves in the sagittal plane.

The most used method in clinical practice for the evaluation of AVR by simple radiography is the Nash-Moe method, although it has some limitations, such as grading from neutral to " ++++ ", with no correlation to the measurement in degrees. ${ }^{13,14}$ The characterization of curves in the sagittal plane is an even greater challenge, since the more severe the curve, the greater the axial rotation and the worse the sagittal plane characterization

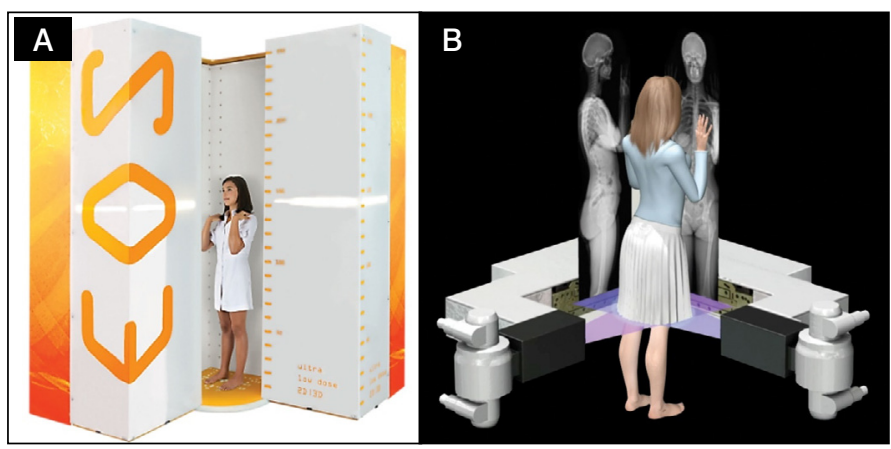

Figure 1. A. Positioning of the patient inside the apparatus booth. B. Illustration showing the simultaneous acquisition of frontal and lateral (biplanar) images in a craniocaudal scan. through lateral radiography. This is because rotation does not allow evaluation of the "true profile" of the soul of the curve, the region of greatest severity of the deformity. This was demonstrated in the study by Péloux et al., who defined the true profile of the soul of the curve through oblique radiographs, characterizing Stagnara's plan d'election. ${ }^{15}$ These parameters are of fundamental importance, as it has been well established that thoracic hypokyphosis is one of the most important events in the pathogenesis of the deformity and, together with axial rotation, is related to curve progression. ${ }^{16}$

The evaluation of these parameters could be performed using sophisticated exams, such as computed tomography (CT) or magnetic resonance (MR), but these present several limitations, including high cost, not allowing the assessment of the patient in the orthostatic position, and, with CT, high doses of radiation. ${ }^{14}$ The issue of exposure to radiation becomes even more relevant in the pediatric population, which generally requires numerous exams during life-long follow-up. ${ }^{17}$ As already mentioned, image acquisition using a biplanar system allows the evaluation of patients in the orthostatic position with exposure to radiation on the order of ten times lower than full-spine radiography. ${ }^{6,7}$ More recently, new protocols using micro-doses have allowed for examinations with up to 5.5 times less radiation than the usual protocol without significant loss of image quality. This protocol is suggested for the patient follow-up phase, with practically negligible doses of ionizing radiation. ${ }^{17,18}$

The biplanar imaging system allows the analysis of all the twodimensional parameters, (Figure 2) like conventional radiography, in addition to three-dimensional analysis through 3D image reconstruction. (Figure 2) The measurement of radiographic parameters of interest in AIS demonstrates heightened accuracy when compared to measurement of images obtained via CT, considering the Cobb value, thoracic kyphosis, and axial rotation. ${ }^{19}$

Using this technology, Newton et al. were able to show the true positioning of the vertebrae in the sagittal plane. The authors evaluated the sagittal angulation of each vertebra in relation to its adjacent vertebra and observed that two-dimensional measurements tend to overestimate thoracic kyphosis measured between T5 and T12 by $11^{\circ}$ on average. In addition to this information, which enables refinement in the surgical correction to the extent that the exact relationship between one vertebra and another are understood, they called attention to the impossibility of comparing preoperative thoracic kyphosis with the postoperative measurement, since derotation of the vertebrae of the soul of the curve is performed during correction. ${ }^{20}$

Besides the usual parameters already studied in radiographs, the biplanar imaging system allows the evaluation of several other parameters, both regional (maximum Cobb, coronal Cobb, sagittal Cobb, plane of maximum curvature (PMC), and the plane formed by the terminal-apical-terminal vertebrae), and local (wedging of the vertebra and disc, rotation in the transversal plane, and pelvic measurements). Additionally, new forms of presentation of the deformity have been developed based on these parameters, principally the plane of maximum curvature (PMC) measured using the orientation of the plane formed by the terminal-apical-terminal vertebrae to the proximal thoracic, main thoracic, and lumbar/ thoracolumbar curves. In the patient with a normal spine, the orientation of the terminal-apical-terminal vertebrae is practically in the midline (zero degrees), since the physiological curves are thoracic kyphosis and lumbar lordosis, which are found in the sagittal plane. In order to facilitate visualization of the deformity in the axial plane, a graphical representation, called the "da Vinci" view, was developed, which allows evaluation of these planes in a more simplified manner. ${ }^{10}$ (Figure 2)

Demonstrating the importance of three-dimensional deformity assessment and its applicability to clinical practice, the Scoliosis Research Society (SRS) established a committee for the development of a 3D AIS classification system. Using data clustering techniques, they identified different curve forms, even among the curves 


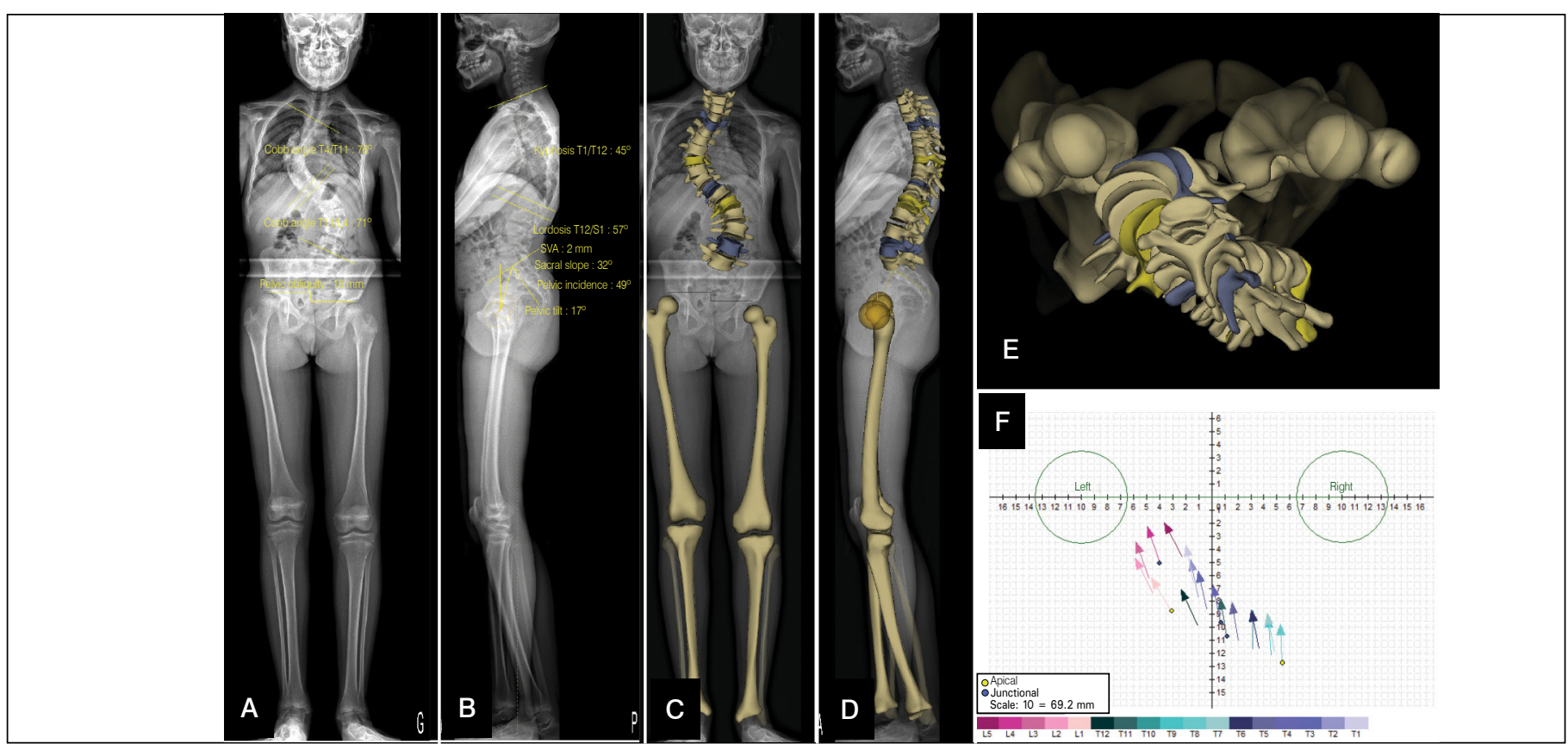

Figure 2. A and B. Two-dimensional radiographic frontal $(A)$ and lateral $(B)$ images of the entire body of a patient with AIS, with measurement of the spinal radiographic parameters of interest; $C$ and $D$. $3 D$ stereoradiographic reconstruction of the bone elements of the spine and lower limbs; $E$. Axial view of the $3 \mathrm{D}$ spinal reconstruction showing the displacement of each vertebra in this plane; F. Diagram showing the true positioning of each vertebra in the axial plane and the vectors of vertebral inclination that denote their degree of rotation.

classified as the same type using the Lenke classification. ${ }^{10}$ Although not yet available, the members of this committee believe that it will allow a better understanding of the aspects of three-dimensional deformity, better define how to correct these parameters, and improve the evaluation of postoperative outcomes. ${ }^{10}$

\section{Adult spinal deformity}

The study of adult spinal deformity (ASD) is arousing interest in light of the aging of the population observed globally. ${ }^{21}$ This deformity is related to very severe functional disability comparable to chronic conditions such as diabetes, cancer, and respiratory and heart disease, ${ }^{21}$ and a considerable portion of patients seek surgical treatment. The evaluation of patients with ASD and treatment planning involve the assessment of well-established radiographic parameters, ${ }^{21-23}$ some of them used in the SRS-Schwab classification, which is the most widely used system and has proven clinical relevance. ${ }^{24}$ This classification system consists of a descriptive component of the type of deformity, including double coronal curve (thoracic and lumbar), thoracic curve, lumbar curve, and deformities without deformity in the coronal plane, in addition to three sagittal modifiers, according to the value of the radiographic parameters related to the sagittal alignment of the spine that are most highly correlated with functional disability, including the sagittal vertical axis (SVA), pelvic tilt (PT), and the discrepancy between pelvic incidence and lumbar lordosis (PI-LL). ${ }^{24}$

All interest in the study of the relationship between sagittal vertebral alignment and pelvic alignment stems from the "cone of economy" concept introduced by Professor Dubousset, which is the narrow margin within which the body is able to remain in balance with minimal effort and without external support. ${ }^{25}$ A recent study sought to evaluate the "cone of economy" concept by investigating the relationship between the line of gravity (LG) of the body and the position of the foot, taking the radiographic parameters of sagittal vertebral alignment of the volunteers into account. It was shown that the anterior inclination of the trunk, represented by an increase in the SVA, leads to pelvic retroversion, with an increase in the PT angle and/or knee flexion, such that the location of the LG does not change in relation to the position of the foot. ${ }^{26}$ Thus, in order to maintain the center of body mass, represented by the LG, in relation to the position of the foot, maintaining the "cone of economy", the loss of sagittal vertebral alignment is accompanied by the recruitment of compensatory mechanisms. ${ }^{27-29}$ The identification of these mechanisms allows for a true interpretation of the vertebral deformity and is essential to the planning of correction surgery in order to optimize postoperative alignment. ${ }^{29}$

Many of the compensatory mechanisms are observed in the spine itself and in the pelvis, including cervical hyperlordosis, thoracic hypokyphosis, and pelvic retroversion, and can be assessed via a panoramic orthostatic radiograph of the entire spine. However, other compensatory mechanisms involving the lower limbs, including changes in hip, knee, and ankle position, ${ }^{27-30}$ cannot be contemplated with conventional spinal imaging exams. Evaluation of patients with ASD using the whole-body biplanar imaging system allows a better understanding of both spinopelvic deformity and recruited compensatory mechanisms, with a complete analysis of sagittal alignment. ${ }^{27,29}$ (Figure 3)

Ferrero et al. conducted a study analyzing sagittal alignment according to whole-body evaluation with images obtained by the biplanar system. ${ }^{29}$ Considering a large sample of individuals with ASD, they observed that the loss of lumbar lordosis and the anterior inclination of the trunk (increase of the SVA and the T1 spinopelvic inclination angle), representing loss of spinal sagittal alignment, were associated with the recruitment of compensatory mechanisms, including pelvic retroversion (an increase in PT), posterior displacement of the pelvis and knee flexion. ${ }^{29}$ (Figure 3) There was a statistically significant correlation between the radiographic spinopelvic parameters and the parameters considered in the evaluation of the compensatory mechanisms of the lower limbs, highlighting the role of these mechanisms in attempting to reduce loss of spinal sagittal alignment and all the associated functional disability. ${ }^{29}$

Since the clinical impact of ASD is associated with the severity of intrinsic deformity in the spine and with the behavior of compensatory mechanisms, a new radiographic parameter was established that allows contemplation both of the loss of spinopelvic sagittal alignment and the compensatory mechanisms, called the global sagittal angle (GSA). ${ }^{31}$ (Figure 3) In a 

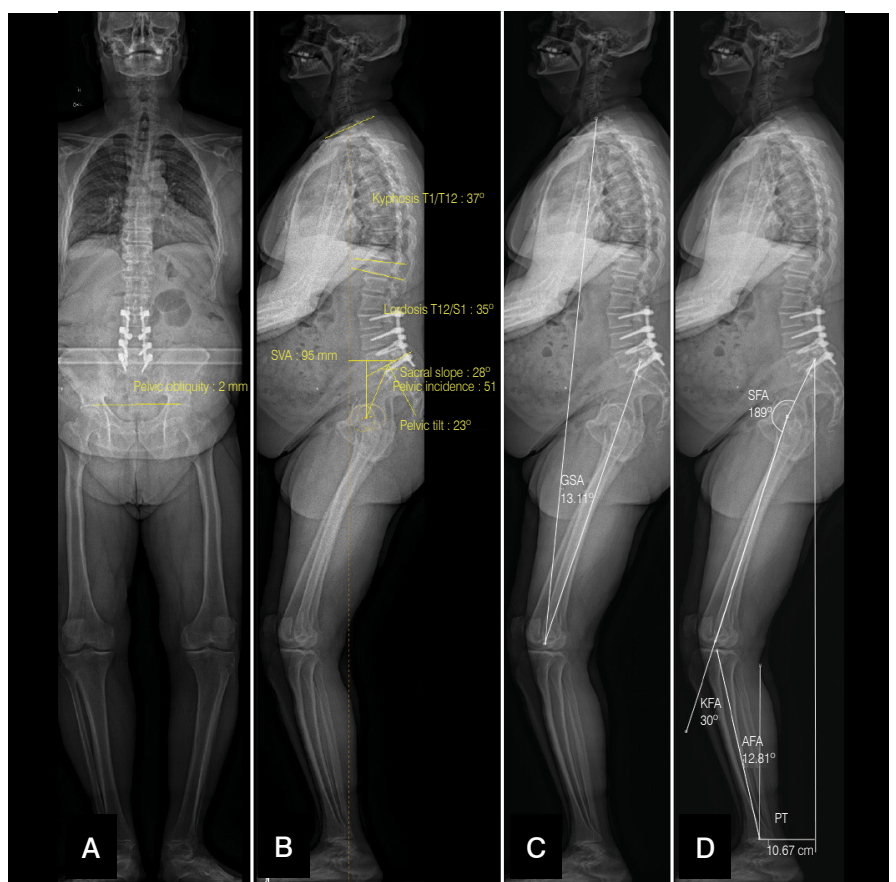

Figure 3. A. Frontal whole-body images of a patient with ASD; B. Lateral whole-body radiographic image of the patient with parameters measurements that indicate the loss of spinopelvic sagittal alignment, including pelvic incidence, pelvic tilt, lumbar lordosis, thoracic kyphosis, and sagittal vertebral axis; C. Measurement of the global sagittal angle (GSA), a radiographic parameter that permits contemplation of the loss of spinopelvic sagittal alignment and the simultaneous recruitment of compensatory mechanisms in the lower limbs; $\mathrm{D}$. Measurement of the radiographic parameters indicative of the compensatory mechanisms in response to loss of sagittal alignment: knee flexion angle (KFA), sacrofemoral angle (SFA), ankle flexion angle (AFA), and posterior displacement of the pelvis (PT). retrospective analysis of 143 patients with ASD who underwent evaluation using biplanar system whole-body imaging, Diebo et al. reported correlations between this new parameter and the Oswestry index and Scoliosis Research Society-22 questionnaire, as well as a significant correlation with the radiographic spinopelvic alignment evaluation parameters (SVA and PT) and with the lower limb compensatory mechanisms (sacrofemoral angle, knee flexion angle, and ankle flexion angle). ${ }^{31}$

\section{CONSIDERATIONS}

The new technology for whole-body radiographic imaging with the capability of 3D reconstruction of bone elements allows a better understanding of spinal deformity with new perspectives for decision making in surgical planning for the treatment of spinal deformities combined with exposure to a dose of radiation absorbed by the patients of around 10 times less than that required for a whole spine $X$-ray. One of the main limitations of spinal image acquisition with this new technology is the inability to conduct the exam with the patient in decubitus, which is important for assessing the flexibility of the deformity (both with lateral inclinations in AIS and simple decubitus to eliminate the effect of the muscles on the deformity). In conclusion, it can be inferred that analysis of the whole-body images obtained via the biplanar system with 3D capacity enables better evaluation of the deformity, the possibility of more complete surgical planning, and with proven lower radiation exposure. There is a lack of studies reporting improved outcomes and safety associated with the treatment of spinal deformities supported by image analysis using this new technology.

All authors declare no potential conflict of interest related to this article.

CONTRIBUTION OF THE AUTHORS: Each author made significant individual contributions to this manuscript. RRP and MTD wrote the manuscript, with the final review conducted by RM. All authors contributed equally to the intellectual concept of the article and approved the final version.

\section{REFERENCES}

1. Charpak G. La detection des particules. Recherche. 1981;128:1384-96.

2. Dubousset J, Charpak G. Dorion I, Skalli W, Lavaste F. Deguise J, et al. A new 2D and 3D imaging approach to musculoskeletal physiology and pathology with low-dose radiation and the standing position: the EOS system. Bull Acad Natl Med. 2005;189(2):287-97.

3. Humbert L, De Guise JA, Aubert B, Godbout B, Skalli W. 3D reconstruction of the spine from biplanar $\mathrm{X}$-rays using parametric models based on transversal and longitudinal inferences. Med Eng Phys. 2009:31(6):681-7.

4. Chaibi $Y$, Cresson T, Aubert B, Hausselle J, Neyret P, Hauger O, et al. Fast 3D reconstruc- tion of the lower limb using a parametric model and statistical inferences and clinical measurements calculation from biplanar X-rays. Comput Methods Biomech Biomed Eng 2012:15(5):457-66.

5. Melhem E, Assi A, Rachkidi RE, Ghanem I. EOS biplanar X-ray imaging: concept, developments, benefits, and limitations. J Child Orthop. 2016;10(1):1-14

6. Kalifa G, Charpak Y, Maccia C, Fery-Lemonnier E, Bloch J, Boussard JM, et al. Evaluation of a new low-dose digital $X$-ray device: first dosimetric and clinical results in children. Pediatr Radiol. 1998:28(7):557-61.

7. Damet J, Fournier P, Monnin P, Sans-Merce M, Ceroni D, Zand T, et al. Occupational and patient exposure as well as image quality for full spine exami- nations with the EOS imaging system. Med Phys. 2014;41(6):063901.

8. Lonstein JE. Adolescent idiopathic scoliosis. Lancet. 1994;344(8934):1407-12.

9. Weinstein SL Natural history Spine (Phila Pa 1976) 1999-24(24) 2592-600.

10. Labelle H, Aubin CE, Jackson R, Lenke L, Newton P, Parent S. Seeing the spine in 3D: how will it change what we do? J Pediatr Orthop. 2011;31(1 Suppl.):S37-45.

11. Lee SM, Suk SI, Chung ER. Direct vertebral rotation: a new technique of three-dimensiona deformity correction with segmental pedicle screw fixation in adolescent idiopathic scoliosis. Spine (Phila Pa 1976) 2004:29(3):343-9

12. Lenke LG, Edwards CC, Bridwell KH. The Lenke classification of adolescent idiopathic scoliosis: how it organizes curve patterns as a template to perform selective fusions of the spine. Spine (Phila Pa 1976). 2003;28(20S):S199-207.

13. Nash CL, Moe JH. A study of vertebral rotation. J Bone Joint Surg Am. 1969:51(2):223-9.

14. Sullivan TB, Bastrom $T$, Reighard $F$, Jeffords $M$, Newton PO. A Novel Method for Estimating Three-Dimensional Apical Vertebral Rotation Using Two-Dimensional Coronal Cobb Angle and Thoracic Kyphosis. Spine Deform. 2017;5(4):244-9.

15. Du Peloux J. Le plan d'election pour l'examen radiologique des cyphoscolioses. Rev Chi Orthop Reparatrice Appar Mot. 1965:51:517-24.

16. Dickson RA, Lawton JO, Archer IA, Butt WP. The pathogenesis of idiopathic scoliosis. Biplanar spinal asymmetry. J Bone Joint Surg Br. 1984;66(1):8-15

17. Newton PO, Khandwala Y, Bartley CE, Reighard FG, Bastrom TP, Yaszay B. New EOS imaging protocol allows a substantial reduction in radiation exposure for scoliosis patients. Spine Deform. 2016;4(2):138-44.

18. Ilharreborde $B$, Ferrero $E$ Alison $M$, Mazda $K$. EOS microdose protocol for the radiological follow-up of adolescent idiopathic scoliosis. Eur Spine J. 2016;25(2):526-31.

19. Glaser DA, Doan J, Newton PO. Comparison of 3-dimensional spinal reconstruction accuracy: biplanar radiographs with EOS versus computed tomography. Spine (Phila Pa 1976). 2012:37(16):1391-7.

20. Newton PO, Fujimori T, Doan J, Reighard FG, Bastrom TP, Misaghi A. Defining the "Three-Dimensional Sagittal Plane" in Thoracic Adolescent Idiopathic Scoliosis. J Bone Joint Surg Am. 2015;97(20):1694-701.

21. Pratali R, Diebo B, Schwab F. Adult spine deformity - an overview of radiographic and clinical considerations. Coluna/Columna. 2017:16(2):149-52

22. Tebet MA. Conceitos atuais sobre equilíbrio sagital e classificação da espondilolise e espondilolise. Rev Bras Ortop. 2014;49(1):3-12

23. Pratali RR, Hennemann SA, Amaral R, Da Silva LECT, De Carvalho MOP, Daher MT et al. Terminologia padronizada da deformidade vertebral do adulto para o Português do Brasil. Coluna/Columna. 2015:14(4):281-5.

24. Terran J, Schwab F, Shaffrey Cl, Smith JS, Devos P, Ames CP, et al. The SRS-Schwab adult spinal deformity classification: assessment and clinical correlations based on a prospective operative and nonoperative cohort. Neurosurgery. 2013;73(4):559-68.

25. Dubousset J. Three-dimensional analysis of the scoliotic deformity. In: Weinstein SL, editors Pediatric Spine: Principles and Practice. New York, NY: Raven Press: 1994

26. Lafage V, Schwab F, Skalli W, Hawkinson N, Gagey PM, Ondra S, et al. Standing balance and sagittal plane spinal deformity Analysis of spinopelvic and gravity line parameters. Spine (Phila Pa 1976). 2008;33(14):1572-8

27. Barrey C, Roussouly P. Le Huec JC, D'Acunzi G, Perrin G Compensatory mechanisms contributing to keep the sagittal balance of the spine. Eur Spine J. 2013;22(Suppl 6):S834-41.

28. Obeid I, Hauger O, Aunoble S, Bourghli A, Pellet N, Vital JM. Global analysis of sagitta spinal alignment in major deformities: correlation between lack of lumbar lordosis and flexion of the knee. Eur Spine J. 2011:20(Suppl 5):S681-5

29. Ferrero $E$, Liabaud B, Challier V, Lafage R, Diebo BG, Vira S. Role of pelvic translation and lower-extremity compensation to maintain gravity line position in spinal deformity. J Neurosurg Spine. 2016;24(3):436-46.

30. Barrey C, Roussouly P, Perrin G, Le Huec JC. Sagittal balance disorders in severe degenerative spine Can we identify the compensatory mechanisms? Eur Spine J. 2011:20(Suppl. 5):S626-33.

31. Diebo BG, Oren JH, Challier V, Lafage R, Ferrero E, Liu S, et al. Global sagittal axis: a step toward full-body assessment of sagittal plane deformity in the human body. $J$ Neurosurg Spine. 2016;25(4):494-9. 